\title{
iBioChina and iBiology: spreading scientific knowledge together
}

\author{
DELL Karen $\mathrm{R}^{1^{*}} \&$ VALE Ronald $\mathrm{D}^{1,2^{*}}$ \\ ${ }^{1}$ iBiology, University of California, San Francisco, CA 94158, USA; \\ ${ }^{2}$ Howard Hughes Medical Institute, Department of Cellular and Molecular Pharmacology, \\ University of California, San Francisco, CA 94158, USA
}

Received September 7, 2015; accepted September 11, 2015; published online September 30, 2015

Citation: Dell KR, Vale RD. iBioChina and iBiology: spreading scientific knowledge together. Sci China Life Sci, 2015, 58: 1180-1182, doi: 10.1007/s11427-015-4938-9

It is becoming increasingly important for the public to understand how new scientific information and technology impact their lives and how scientists obtain new knowledge. Without this understanding, how do people know if global warming is real or if it is safe to eat genetically modified crops? Dr. Chen ZhangLiang, the Vice President of China Association of Science and Technology (CAST), conveyed this message in his talk at the Chinese Society for Cell Biology (CSCB) Biennial Conference held in Shenzhen in April, 2015. Dr. Chen emphasized the importance of spreading scientific knowledge within China's scientific community. iBioChina.org is a project that is addressing this challenge and was the focus of the meeting session in which Dr. Chen spoke. iBioChina, which is directed by Professor Miao Long of the Institute of Biophysics, Chinese Academy of Sciences, is a collection of online videos by the world's leading biologists which are made freely available to students, as well as senior scientists, throughout China.

Dr. Dell Karen was invited by Professor Miao to attend the CSCB meeting to introduce iBiology, which is the partner organization of iBioChina. iBiology is a non-profit organization based at the University of California, San Francisco (UCSF) and affiliated with the American Society for Cell Biology. iBiology produces high quality biology videos and disseminates them online and free of charge at iBiology.org, on YouTube, and on iTunesU. More details on the iBiology project and videos are described at the end of this article. In 2010, Miao approached Dr. Vale Ronald, the

*Corresponding author (email: Karen.Dell@ucsf.edu; Ron.Vale@ucsf.edu) founder of iBiology, with the suggestion of establishing a sister site in China to facilitate the viewing of iBiology videos online, by Chinese students and scientists. A year later, iBioChina was launched. Since then, iBiology and iBioChina have been collaborating to bring a wide selection of freely accessible biology videos to viewers across China. iBioChina is planning to grow in terms of educational outreach in China and to extend its partnership with iBiology in the coming several years.

The highlight of Dr. Dell's visit to China was talking to students and teachers who have watched iBioChina and iBiology videos. At the CSCB meeting, Dr. Dell was very excited to speak to teachers who have used the videos in their classrooms. Professor Guangshuo Ou of Tsinghua University explained how he watched an iBiology lecture by professor Robert Horvitz together with his students. Professor Horvitz won the Nobel Prize for his work on programmed cell death in the nematode $C$. elegans and Ou's lab also uses $C$. elegans for their research. Watching Horvitz's lecture together provided an opportunity for Ou to ask the students if they understood the experiments Horvitz described and why he was doing them. It was also good practice for students who may attend international conferences to listen to a scientific talk in English. Ou plans to continue this exercise with other videos highlighting famous discoveries.

Students are also using iBiology videos to prepare for class and to learn new material. When Dr. Dell was invited by Professor Xuebiao Yao to visit the University of Science 
and Technology of China, she was delighted to hear from a student who told her how much he benefitted from the iBiology Light Microscopy Course and thought that it is by far the best microscopy course available online. He particularly liked the mix of lectures by expert microscopists and labs and practical tips.

iBiology courses such as the microscopy course and a "flipped classroom" cell biology course in which students watch a video before coming to class and class time is dedicated to discussion, are currently only available via iBiology.org. iBiology is working with Professor Miao to post these courses on iBioChina making them more easily accessible to viewers in China. In addition, lectures targeted to high school students and educational resources for teachers such as suggested discussion topics and assessments will be available on iBioChina.org soon. Many videos are available now with English subtitles and Chinese subtitles will be available for some videos in the future.

iBioChina is expanding its reach by taking advantage of the fact that many millions of people routinely access the Internet via their mobile phones or other devices. iBioChina is now posting daily videos to WeChat (ID: ibiochina, for more information, please visit http://eqxiu.com/s/ fO4oiT72), making it extremely easy to watch a new biology lecture everyday. Outreach via channels such as WeChat, Youku and Tencent video is a powerful mechanism to reach students and scientists, as well as viewers outside of academic circles.

With the continuing support of scientists like Dr. Chen and institutions such as CAST, CSCB and the Biophysical Society of China, iBioChina will continue to grow and improve. As the content on the iBioChina.org site increases

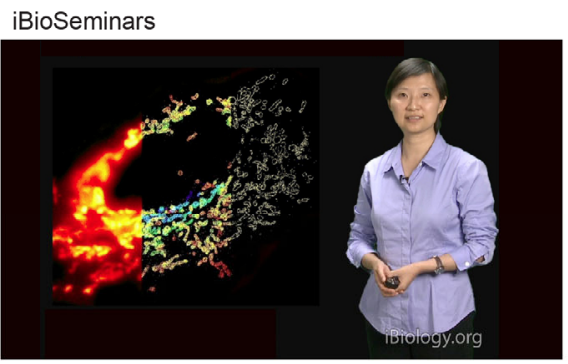

Research seminars from leading biologists

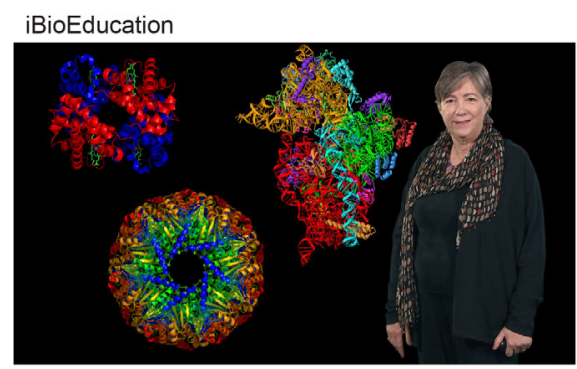

Resources for students and educators and outreach expands, iBioChina has the potential to become a leading source for students, trainees, scientists and the public to learn about exciting new biological research as well as other topics of interest to the scientific community. iBiology.org is also pleased to grow its connections and interactions with Chinese scientists and educators.

The iBiology Project (Figure 1). iBiology (originally called iBioSeminars) was founded in 2006 by Professor Vale, Howard Hughes Medical Institute Investigator at UCSF and recipient of the 2012 Albert Lasker Basic Medical Research Award. The major goal of the project is to make scientific talks from leading scientists accessible to students and scientists throughout the world, free-of-charge. This project serves an important role in the life sciences, since most educational institutions in the US and around the world do not have the funds or the reputation to attract high profile scientists. The target audience for iBiology is college students through senior scientists with increasing content for high school students. Pioneering the use of "green screen" technology for filming scientific talks, iBiology now hosts over 500 videos from over 200 scientists, including 40 videos by Nobel Laureates and 160 by members of the National Academies of Sciences. To encourage participation by young scientists, iBiology recently launched a new video series featuring talented $\mathrm{PhD}$ students and postdocs selected by an international competition. Winners attended a science communication workshop at the Alan Alda Center for Communicating Science at Stony Brook University and their research stories were recorded for release on iBiology and iBioChina. The Young Scientist competition will continue in 2016 and iBiology encourages applications

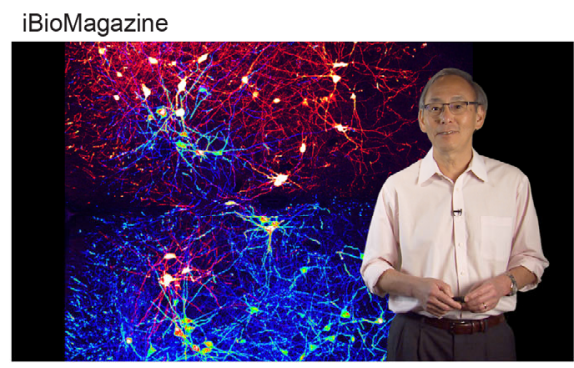

Short talks on discoveries, career advice \& more

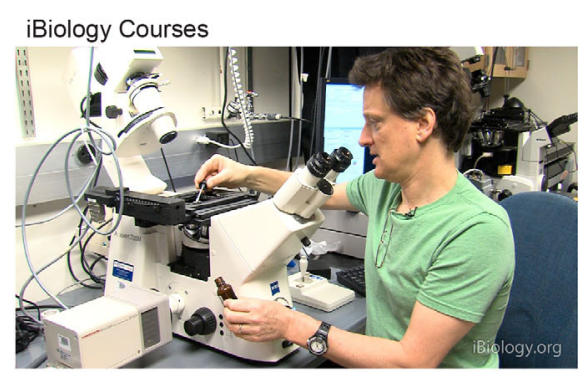

In depth microscopy courses \& more

Figure 1 Screenshots taken from videos in each of the iBiology video collections: iBioSeminars, iBioMagazine and iBioEducation. The iBioEducation section includes a popular light microscopy course. 
from China. The iBiology Project is funded by the National Science Foundation and the National Institutes of Health and receives additional assistance from the American Society for Cell Biology, the Lasker Foundation, UCSF, the European Molecular Biology Organization, the Howard Hughes Medical Institute, and the Marine Biological Laboratory. iBiology now has 50,000 subscribers and social media followers and two million views of video content per year, with viewers from 180 countries. The project is being used in college and graduate level education in a "flipped classroom" model, where students watch a video as homework and then discuss the scientist's work with their instructor. International outreach is extremely important for the iBiology project and we are pleased to have a strong connection with iBioChina (Please visit www.iBiology.org and www.iBioChina.org to learn more).

Open Access This article is distributed under the terms of the Creative Commons Attribution License which permits any use, distribution, and reproduction in any medium, provided the original author(s) and source are credited.

\section{Supporting Information}

Video S1 The presentation entitled "How can we sense infection? Helping to treat sepsis" was given by Dr. Jianjin Shi from the National Institute of Biological Sciences, Beijing (professor Feng Shao's lab). Shi was one of five speakers selected by iBiology for the 2015 Young Scientist Seminars (or visit http://v.qq.com/page/s/i/j/s01686zrwij.html; http://www.ibiology.org/ibioseminars/young-scientist-seminar-series.html)

The supporting information is available online at life.scichina.com and link.springer.com. The supporting materials are published as submitted, without typesetting or editing. The responsibility for scientific accuracy and content remains entirely with the authors. 